\title{
DISCUSSION \\ Application of bentonitic clays in suspension fertilizer formulations
}

\author{
by J. Hanna and H.R. Gonzalez
}

\author{
MINERALS \& METALLURGICAL PROCESSING \\ Vol. 7, No. 2, May 1990, pp. 90-93
}

\section{Discussion by N.L. Hargett}

Dear Dr. Hanna:

As discussed in our phone conversation, we are enclosing a suggested revision to the paper, "Application of Bentonitic Clays in Suspension Fertilizer Formulations," published in MINERAL \& METALLURGICALPROCESSING, May 1990. The revision will replace the second paragraph in the article.

The reason for the revision is that suspensions have decreased in market share since 1984 and at present comprise an estimated $25 \%$ to $30 \%$ of fluid mixtures. This represents $6 \%$ to $7 \%$ of all fluids and only $2 \%$ to $3 \%$ percent of all fertilizers. Based on national surveys conducted by the Association of American Plant Food Control Officials (AAPFCO), suspensions comprised an estimated $25 \%$ of all fluid mixtures in 1974 , $33 \%$ in $1976,35 \%$ in $1980,40 \%$ in 1984 , and $36 \%$ in 1988 .

N.L Hargett is a research engineer at the Mineral Resources Institute, College of Engineering, University of Alabama, Tuscaloosa, AL.
Revision to "Application of Bentonitic Clays in Suspension Fertilizer Formulations."

Suspension fertilizers are an important segment of the fertilizer industry in the United States. Suspensions allow higher concentrations of nutrients $\left(\mathrm{N}, \mathrm{P}_{2} \mathrm{O}_{5}, \mathrm{~K}_{2} \mathrm{O}\right)$ than clear liquid solution fertilizers. $\mathrm{K}_{2} \mathrm{O}$ content of solutions is limited to about $10 \%$, while suspensions can contain more than $30 \% \mathrm{~K}_{2} \mathrm{O}$. Suspensions can tolerate greater variations in temperature than solutions. In suspensions, if crystallization occurs, the crystals can remain suspended in a clay jell instead of settling as they would in solutions. Solubility is not a limiting factor in suspensions, since complete solubility of phosphate is not required. This allows a wider range of phosphate materials to be used. Also, materials commonly used in formulating suspensions are less expensive and more widely available than those for clear liquids (Getsiner et al., 1984). 